Pacific Journal of Mathematics

ON UNIVERSAL TREELIKE CONTINUA 


\section{ON UNIVERSAL TREE-LIKE CONTINUA}

J. W. ROGERS, JR.

R. M. Schori has conjectured that if $T$ is a tree, but not an arc, then there is no universal $T$-like continuum. We show that if $G$ is a finite collection of trees and there is a universal $G$-like continuum, then each element of $G$ is an arc. It then follows that if $G$ is a finite collection of one-dimensional (connected) polyhedra, and there is a universal $G$-like continuum, then each element of $G$ is an arc.

1. Definitions. By a continuum here we mean a compact connected metric space; by a polyhedron, a nondegenerate (finitely) triangulable continuum. In a metric space, the distance between two points, $A$ and $B$, is denoted by $d(A, B)$, and a similar notation is used for distances between points and point sets. The closure of a point set $K$ is denoted by $\bar{K}$.

The point $P$ of the continuum $M$ is a junction point of $M$ if and only if $M-P$ has at least three components.

A tree is a polyhedron that contains no simple closed curve. The point $P$ of the tree $T$ is an endpoint of $T$ if and only if $P$ is a noncutpoint of $T$.

The continuum $M$ is an $n$-od if and only if $n$ is a positive integer greater than 2 and there is a point $P$ such that $M$ is the sum of $n$ arcs, each two intersecting only at $P$, which is an endpoint of both of them. If $P Q$ is one of the $n$ arcs, then $P Q-P$ is called a ray of $M$.

If $\varepsilon>0$, a transformation $f$ from a metric space $X$ onto a space $Y$ is called an $\varepsilon-m a p$ if and only if $f$ is continuous and if $P$ is a point of $Y$, then $f^{-1}(P)$ has diameter $<\varepsilon$. The space $X$ is $Y$-like if and only if there is an $\varepsilon$-map from $X$ onto $Y$ for each $\varepsilon>0$. If $G$ is a collection of spaces, the metric space $X$ is G-like if and only if for each $\varepsilon>0$, there is an $\varepsilon$-map from $X$ onto some element of $G$ [1].

\section{Lemmas.}

Lemma 1. If $P$ is a junction point of the subcontinuum $M$ of the continuum $U$, then there is an open set $R$ in $U$ containing $P$ such that if $R^{\prime}$ is an open subset of $R$ containing $P$, then there is a positive number $\varepsilon$ such that every $\varepsilon$-map f from $U$ onto a tree, $T$, throws some point of $R^{\prime}$ onto a junction point of $T$.

Proof. Since $M-P$ has at least three components, $M-P$ is the sum of three mutually separated point sets, $K_{1}, K_{2}$, and $K_{3}$. For 
each $i \leqq 3$, let $P_{i}$ denote a point of $K_{i}$. Let $R$ denote an open set in $U$ that contains $P$ but not $P_{1}, P_{2}$, or $P_{3}$, and suppose $R^{\prime}$ is any open subset of $R$ that contains $P$. Let $\varepsilon$ denote a positive number less than the distance between any two of the sets $K_{i}-K_{i} \cdot R^{\prime}(i \leqq 3)$, and also less than $d\left(P_{i}, K_{j}\right)$, for $i \leqq 3, j \leqq 3, i \neq j$.

Now, suppose $f$ is an $\varepsilon$-map from $U$ onto a tree $T$. Since, if $i \leqq 3, \bar{K}_{i}$ is a continuum, $f\left(\bar{K}_{i}\right)$ contains an arc $\alpha_{i}$ from $f\left(P_{i}\right)$ to $f(P)$. If no two of these arcs intersect except at $f(P)$, then $f(P)$ is a junction point of $T$. If the arc $\alpha_{1}$ intersects the arc $\alpha_{2}$ in a point distinct from $f(P)$, let $Q$ denote the first point of $\alpha_{2}$ on $\alpha_{1}$ from $f\left(P_{1}\right)$ to $f(P)$. Clearly, $Q$ must also be the first point of $\alpha_{1}$ on $\alpha_{2}$ from $f\left(P_{2}\right)$ to $f(P)$. Hence the three arcs, $[f(P), Q]$ and $\left[Q, f\left(P_{1}\right)\right]$ on $\alpha_{1}$, and $\left[Q, f\left(P_{2}\right)\right]$ on $\alpha_{2}$, intersect only in the point $Q$, and $Q$ is a junction point of $T$. Moreover, $Q$ is a point of $f\left(R^{\prime}\right)$, since $f^{-1}(Q)$ intersects both $K_{1}$ and $K_{2}$, but cannot intersect both $K_{1}-K_{1} \cdot R^{\prime}$ and $K_{2}-K_{2} \cdot R^{\prime}$.

A similar argument suffices in case some other pair of the arcs $\alpha_{1}, \alpha_{2}$, and $\alpha_{3}$ intersect in a point distinct from $f(P)$.

Lemma 2. If $N$ is an n-od with junction point $P$, lying in a continuum $U$, there is a positive number $\varepsilon$ such that if $f$ is an $\varepsilon$-map from $U$ onto a tree $T$ with at most one junction point then (1) $T$ is a j-od with junction point $Q$, and $j \geqq n$, (2) each endpoint of $N$ is thrown by $f$ into some ray of $T$, but no two into the same ray, and (3) if $E$ is an endpoint of $N$ and $f(P)$ lies in the ray of $T$ that contains $f(E)$, then $f(P)$ lies in the arc in $T$ from $Q$ to $f(E)$.

Proof. By Lemma 1 there is an open set $R$ in $U$ containing $P$ and a positive number $\varepsilon^{\prime}$ such that (1) $\bar{R}$ contains no endpoint of $N$ and (2) if $f$ is an $\varepsilon^{\prime}$-map from $U$ onto a tree $T_{0}$, then $f(R)$ contains a junction point of $T_{0}$. Let $P_{1}, \cdots, P_{n}$ denote the endpoints of $N$ and, for each $i \leqq n$, let $Z_{i}$ denote the ray of $N$ that contains $P_{i}$. Let $\varepsilon$ denote a positive number less than each of the numbers $\varepsilon^{\prime}$, $d\left(P_{i}, R\right)$, and $d\left(P_{i}, N-Z_{i}\right)$, for $i \leqq n$, and suppose that $f$ is an $\varepsilon$-map from $U$ onto a tree $T$ with at most one junction point.

Since $f$ is also an $\varepsilon^{\prime}$-map from $U$ onto $T, f(R)$ contains a junction point $Q$ of $T$. Hence $T$ is, for some positive integer $j$, a $j$-od. Now, if $i \leqq n, d\left(P_{1}, R\right)>\varepsilon$ and $Q$ is in $f(R)$, so $f\left(P_{i}\right) \neq Q$, and $f\left(P_{i}\right)$ lies in a ray of $T$.

Suppose $i$ and $k$ are two integers such that $f\left(P_{i}\right)$ and $f\left(P_{k}\right)$ lie in the same ray of $T$. The are in $T$ from $f\left(P_{i}\right)$ to $f\left(P_{k}\right)$ must contain $f(P)$, for otherwise either $f\left(Z_{i}\right)$ contains $f\left(P_{k}\right)$ or $f\left(Z_{k}\right)$ contains $f\left(P_{i}\right)$, neither of which is possible, since $d\left(P_{i}, N-Z_{i}\right)>\varepsilon$ and $d\left(P_{k}, N-Z_{k}\right)>\varepsilon$. But then if $m \leqq n$ and $i \neq m \neq k$, either (1) $f\left(P_{m}\right)$ lies in $f\left(Z_{i}+Z_{k}\right)$ or (2) $f\left(P_{i}+P_{k}\right)$ intersects $f\left(Z_{m}\right)$, neither of which is possible. So the 
images of different endpoints of $N$ lie in different rays of $T$, and $j \geqq n$.

Finally, suppose $i \leqq n$ and $f(P)$ lies in the ray $W$ of $T$ that contains $f\left(P_{i}\right)$, but $f(P)$ is not on the arc in $T$ from $Q$ to $f\left(P_{i}\right)$. Then $f\left(P_{i}\right)$ is on the arc in $T$ from $Q$ to $f(P)$. So, if $k \leqq n$, and $k \neq i$, then since $f\left(P_{k}\right)$ is not in $W, f\left(Z_{k}\right)$ contains $f\left(P_{i}\right)$. But $d\left(P_{i}, N-Z_{i}\right)>\varepsilon$.

Lemma 3. Suppose (1) $I_{1}$; $I_{2}$; and $I_{3}$ are the intervals in the plane with endpoints $(-1,1),(-1,-1) ;(-1,0),(1,0)$; and $(1,1),(1,-1)$, respectively, and (2) $H=I_{1}+I_{2}+I_{3}$. Then if $T$ is any tree with at least two junction points, and $\varepsilon>0$, there is an $\varepsilon$-map from $H$ onto $T$.

Proof. Let $A$ and $B$ denote the points $(-1,0)$ and $(1,0)$, respectively. Since $T$ has two junction points, $T$ contains an arc $\alpha$ whose endpoints, $X$ and $Y$, are junction points of $T$, but no other point of $\alpha$ is a junction point of $T$. Let $E$ denote the sum of all the components of $T-X$ that do not contain $\alpha-X$. Then $E$ contains two mutually exclusive arcs $\beta_{1}$ and $\beta_{2}$ such that if $i \leqq 2$, then $\beta_{i}$ contains no junction point of $T$, and one endpoint of $\beta_{i}$ is an endpoint of $T$. If $i \leqq 2$, let $Q_{i}$ denote the endpoint of $\beta_{i}$ that is not an endpoint of $T$. Then $\left[E-\left(\beta_{1}+\beta_{2}\right)\right]+X+Q_{1}+Q_{2}$ is a tree.

Now, suppose $\varepsilon>0$. Let $C_{1} ; D$; and $C_{2}$ denote the subintervals of $I_{1}$ with endpoints $(-1,1),(-1, \varepsilon / 2) ;(-1, \varepsilon / 2),(-1,-\varepsilon / 2)$; and $(-1$, $-\varepsilon / 2),(-1,-1)$, respectively. There is a continuous transformation $g_{1}$ from $I_{1}$ onto $E+X$ such that (1) if $i \leqq 2, g_{1} \mid C_{i}$ is a homeomorphism from $C_{i}$ onto $\beta_{i}$, (2) $f(A)=X$, and (3) $f(D)=\left[E-\left(\beta_{1}+\beta_{2}\right)\right]+X+Q_{1}+Q_{2}$. Clearly, $g_{1}$ is an $\varepsilon$-map. Similarly, there is an $\varepsilon$-map from $I_{3}$ onto $[T-(E+\alpha)]+B$ which may be combined with a homeomorphism from $I_{2}$ onto $\alpha$ to obtain an $\varepsilon$-map from $H$ onto $T$.

\section{Theorems.}

THEOREM 1. If $k$ is a positive integer and $G$ is a collection each element of which is a tree with not more than $k$ junction points, but some element of $G$ has two junction points, then there is no universal G-like continuum.

Proof. Suppose $U$ is a universal G-like continuum. Then by Lemma 3 , the continuum $H$ defined in Lemma 3 is $G$-like, and so $U$ contains a continuum $H^{\prime}$ homeomorphic to $H$. Let $T$ denote an element of $G$ such that no element of $G$ has more junction points than $T$, and let $j$ denote the number of junction points of $T$. Let $T_{0}$ denote the continuum obtained from $T$ by replacing, with a pseudo-arc, each arc in $T$ which is maximal with respect to the property that each interior 
point of it is of order 2, in such a way that $T_{0}$ is $T$-like, and hence $G$-like. Again, $U$ contains a continuum $T^{\prime}$ homeomorphic to $T_{0}$.

Suppose that one of the junction points of $H^{\prime}$ is not also a junction point of $T^{\prime}$. Then $U$ contains at least $j+1$ points $P_{1}, P_{2}, \cdots P_{j+1}$ each of which is a junction point of a subcontinuum of $U$. By successive applications of Lemma 1, there is a positive number $\varepsilon$ and a sequence $R_{1}, R_{2}, \cdots R_{j+1}$ of open sets in $U$ such that (1) $d\left(R_{i}, R_{n}\right)>\varepsilon$, for $i \leqq j+1, n<j+1$, and $i \neq n$, and (2) if $f$ is an $\varepsilon$-map from $U$ onto a tree, $T$, then if $i \leqq j+1, f\left(R_{i}\right)$ contains a junction point, $J_{i}$, of $T$. Note that the points $J_{1}, J_{2}, \cdots, J_{j+1}$ must all be distinct; hence $T$ must have at least $j+1$ junction points. But since $U$ is $G$-like, $U$ can be $\varepsilon$-mapped onto some tree in $G$, and no tree in $G$ has $j+1$ junction points. Thus we have a contradiction, and both junction points, $A$ and $B$, of $H^{\prime}$ are also junction points of $T^{\prime}$.

So $U$ contains both an arc from $A$ to $B$, and a continuum $\left(T^{\prime}\right)$ that contains $A$ and $B$, but no arc from $A$ to $B$. Since $U$ is treelike, and so hereditarily unicoherent, this is impossible.

Thus, there is no universal $G$-like continuum.

THEOREM 2. If $G$ is a finite collection each element of which is a tree, and there is a universal G-like continuum, then each element of $G$ is an arc.

Proof. Suppose some element of $G$ is not an arc, but $U$ is a. universal $G$-like continuum. If some element of $G$ has two junction points, then Theorem 1 is contradicted. Thus each element of $G$ is an arc or, for some $n$, an $n$-od. Let $n$ denote the greatest positive integer $j$ such that $G$ contains a $j$-od. Then $U$ contains (1) an $n$-od $N$, and (2) a continum $H$ which is the sum of $n$ pseudo-arcs, all joined at only one point. By arguments used in the proof of Theorem 1 , the junction point, $P$, of $N$ is also the junction point of $H$.

Let (1) $\varepsilon_{1}$ denote a positive integer for the subcontinuum $N$ of $U$ as in Lemma 2, (2) $\varepsilon_{2}$ and $R$ denote a positive number and an open set in $U$, respectively, such that $R$ contains $P$, and if $E$ is an endpoint. of $N$, then $d(E, R)>\varepsilon$, and (3) $C$ denote the component of $U \cdot R$ that contains $P$.

$\bar{C}$ is a subset of $N$, for suppose $A$ is a point of $\bar{C}$ not in $N$. Let $\varepsilon$ denote a positive number less than $\varepsilon_{1}, \varepsilon_{2}$, and $d(A, N)$. Since $U$ is $G$-like, there is an $\varepsilon$-map $f$ from $U$ onto an element $T$ of $G$. Since $\varepsilon<\varepsilon_{1}$ we have, using Lemma 2 , that (1) $T$ is an $n$-od with junction point $Q$, (2) each ray of $T$ contains the image of one, and only one, endpoint of $N$, and (3) there is an endpoint $E$ of $N$ such that $f(P)$ lies in the arc in $T$ from $Q$ to $f(E)$. Since $d(A, N)>\varepsilon, f(A)$ does not intersect $f(N)$, so there is an endpoint $E^{\prime}$ of $N$ such that $f\left(E^{\prime}\right)$ 
lies in the arc in $T$ from $Q$ to $f(A)$. Since $\bar{C}$ is a continuum that contains $A$ and a point of $f^{-1}(Q), f(\bar{C})$ contains $f(A)$ and $Q$, and so $f(\bar{C})$ contains $f\left(E^{\prime}\right)$. But since $d\left(E^{\prime}, C\right)>\varepsilon$, this is impossible.

Thus $\bar{C}$ is a subset of $N$. Since the component $C^{\prime}$ of $H \cdot R$ that contains $P$ is a subset of $C, \bar{C}^{\prime}$ contains an arc. But $H$ itself contains no arc, and we have a contradiction.

THEOREM 3. If $G$ is a finite collection each element of which is a one-dimensional polyhedron, and there is a universal G-like continuum, then each element of $G$ is an arc.

Proof. If some element of $G$ contains a simple closed curve, then by a theorem of M.C. McCord [2, Th. 4, p. 72], there is no universal $G$-like continuum. So each element of $G$ is a tree, and by Theorem 2 , each element of $G$ is an arc.

We note that if each element of $G$ is an arc, there is a universal G-like continuum [3].

\section{REFERENCES}

1. S. Mardešić and J. Segal, e-mappings onto polyhedra, Trans. Amer. Math. Soc. 109 (1963), 146-164.

2. M. C. McCord, Universal $\mathscr{P}$-like compacta, Michigan Math. J. 13 (1966), 71-85.

3. R. M. Schori, A universal snake-like continuum, Proc. Amer. Math. Soc. 16 (1965), 1313-1316.

4. Universal spaces, Proceedings of the Second Prague Topological Symposium, 1966, 320-322.

Received November 18, 1968.

EMORY UNIVERSITY 



\section{PACIFIC JOURNAL OF MATHEMATICS}

\section{EDITORS}

H. ROYDEN

Stanford University

Stanford, California

\section{RichaRd PIERCE}

University of Washington Seattle, Washington 98105
J. DugundJI

Department of Mathematics

University of Southern California

Los Angeles, California 90007

BASIL GORDON

University of California

Los Angeles, California 90024

\section{ASSOCIATE EDITORS}
E. F. BECKENBACH
B. H. NeUMANN
F. WOLF
K. YOSHIDA

\section{SUPPORTING INSTITUTIONS}

UNIVERSITY OF BRITISH COLUMBIA CALIFORNIA INSTITUTE OF TECHNOLOGY

UNIVERSITY OF CALIFORNIA

MONTANA STATE UNIVERSITY

UNIVERSITY OF NEVADA

NEW MEXICO STATE UNIVERSITY

OREGON STATE UNIVERSITY

UNIVERSITY OF OREGON

OSAKA UNIVERSITY

UNIVERSITY OF SOUTHERN CALIFORNIA

\author{
STANFORD UNIVERSITY \\ UNIVERSITY OF TOKYO \\ UNIVERSITY OF UTAH \\ WASHINGTON STATE UNIVERSITY \\ UNIVERSITY OF WASHINGTON \\ AMERICAN MATHEMATICAL SOCIETY \\ CHEVRON RESEARCH CORPORATION \\ TRW SYSTEMS \\ NAVAL WEAPONS CENTER
}

The Supporting Institutions listed above contribute to the cost of publication of this Journal, but they are not owners or publishers and have no responsibility for its content or policies.

Mathematical papers intended for publication in the Pacific Journal of Mathematics should be in typed form or offset-reproduced, double spaced with large margins. Underline Greek letters in red, German in green, and script in blue. The first paragraph or two must be capable of being used separately as a synopsis of the entire paper. It should not contain references to the bibliography. Manuscripts, in duplicate if possible, may be sent to any one of the four editors. Please classify according to the scheme of Math. Rev. 36, 1539-1546. All other communications to the editors should be addressed to the managing editor, Richard Arens, University of California, Los Angeles, California, 90024.

50 reprints are provided free for each article; additional copies may be obtained at cost in multiples of 50 .

The Pacific Journal of Mathematics is published monthly. Effective with Volume 16 the price per volume (3 numbers) is $\$ 8.00$; single issues, $\$ 3.00$. Special price for current issues to individual faculty members of supporting institutions and to individual members of the American Mathematical Society: $\$ 4.00$ per volume; single issues $\$ 1.50$. Back numbers are available.

Subscriptions, orders for back numbers, and changes of address should be sent to Pacific Journal of Mathematics, 103 Highland Boulevard, Berkeley, California, 94708.

PUBLISHED BY PACIFIC JOURNAL OF MATHEMATICS, A NON-PROFIT CORPORATION

Printed at Kokusai Bunken Insatsusha (International Academic Printing Co., Ltd.), 7-17. Fujimi 2-chome, Chiyoda-ku, Tokyo, Japan. 


\section{Pacific Journal of Mathematics}

\section{Vol. 30, No. $3 \quad$ November, 1969}

Willard Ellis Baxter, Topological rings with property $(Y) \ldots \ldots \ldots \ldots . \ldots 5$

Sterling K. Berberian, Note on some spectral inequalities of $C . R$.

Putnam ..................................... 573

David Theodore Brown, Galois theory for Banach algebras . ........... 577

Dennis K. Burke and R. A. Stoltenberg, A note on p-spaces and Moore spaces ........................................ 601

Rafael Van Severen Chacon and Stephen Allan McGrath, Estimates of positive contractions....................................... 609

Rene Felix Dennemeyer, Conjugate surfaces for multiple integral problems in the calculus of variations ........................... 621

Edwin O. Elliott, Measures on countable product spaces.............. 639

John Moss Grover, Covering groups of groups of Lie type .............. 645

Charles Lemuel Hagopian, Concerning semi-local-connectedness and cutting in nonlocally connected continua .................. 657

Velmer B. Headley, A monotonicity principle for eigenvalues ........... 663

John Joseph Hutchinson, Intrinsic extensions of rings . . . . . . . . . . . . . 669

Harold H. Johnson, Determination of hyperbolicity by partial

prolongations .................................. 679

Tilla Weinstein, Holomorphic quadratic differentials on surfaces in $E^{3} \ldots 697$

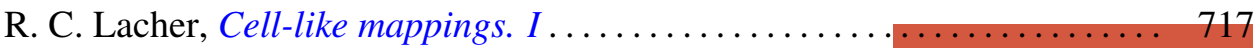

Roger McCann, A classification of centers

Curtis L. Outlaw, Mean value iteration of nonexpansive mappings in a

Banach space...

Allan C. Peterson, Distribution of zeros of solutions of a fourth order

differential equation.

Bhalchandra B. Phadke, Polyhedron inequality and strict convexity .. 765 Jack Wyndall Rogers Jr., On universal tree-like continua .

Edgar Andrews Rutter, Two characterizations of quasi-Frobenius rings

G. Sankaranarayanan and C. Suyambulingom, Some renewal theorems concerning a sequence of correlated random variables...

Joel E. Schneider, A note on the theory of primes........ . .

Richard Peter Stanley, Zero square rings .................

Edward D. Tymchatyn, The 2-cell as a partially ordered space

Craig A. Wood, On general Z.P.I.-rings................ 